See Article page 185 .

\section{Commentary: Interesting...maybe not ready for prime time?}

\author{
Stephanie H. Chang, MD
}

While there has been significant growth in use of staplers for ligation of vessels (ie, minimally invasive lobectomy) or gastrointestinal anastomoses (ie, circular end-to-end anastomosis during an esophagectomy), there remains a paucity of options for mechanical or stapled vascular anastomoses. Currently, cardiothoracic surgery cases that require vascular anastomoses are performed using a handsewn technique. Some of the literature has evaluated the possibility of using a circular end-to-end anastomosis stapler for prosthetic graft to graft anastomoses, ${ }^{1}$ but that still remains rarely used and was not described for primary vascular anastomoses.

In this paper, Shi and colleagues ${ }^{2}$ describes the use of using a linear mechanical stapler to help expedite pulmonary artery anastomoses, particularly in the setting of lung transplant. They performed 3 in vitro anastomoses, with the creation of arterial flaps (as shown in Figure 1 of their paper), and using a linear stapler to anastomose the posterior flap and then the anterior flap. Next, the 2 commissures are closed using prolene. In those 3 experiments, no leaks were present from the anastomosis. They also used this technique in 1 patient with chronic obstructive pulmonary disease. Notably, they were unable to use this technique for the posterior wall due to lack of space after the bronchial anastomosis. However, they were able to use it for the anterior wall with no complications.

While the authors should be commended for their innovate thinking and novel approach toward performing a

From the Department of Cardiothoracic Surgery, New York University Langone Health, New York, NY.

Disclosures: The author reported no conflicts of interest.

The Journal policy requires editors and reviewers to disclose conflicts of interest and to decline handling or reviewing manuscripts for which they may have a conflict of interest. The editors and reviewers of this article have no conflicts of interest.

Received for publication July 23, 2021; revisions received July 23, 2021; accepted for publication July 30, 2021; available ahead of print Aug 4, 2021.

Address for reprints: Stephanie H. Chang, MD, Division of Thoracic Surgery, Department of Cardiothoracic Surgery, New York University Langone Health, 530 First

Ave, Suite 9V, New York, NY 10016 (E-mail: stephanie.chang@nyulangone.org). JTCVS Techniques 2021;9:190-1

2666-2507

Copyright (C) 2021 The Author(s). Published by Elsevier Inc. on behalf of The American Association for Thoracic Surgery. This is an open access article under the CC BY-NC-ND license (http://creativecommons.org/licenses/by-nc-nd/4.0/). https://doi.org/10.1016/j.xjtc.2021.07.024

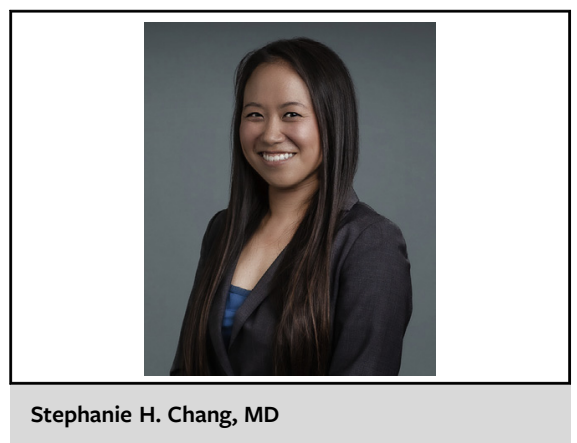

CENTRAL MESSAGE

While this technique for pulmo-

nary artery anastomosis is novel,

further developments are

needed before clinical use in a

specific patient population un-

dergoing lung transplant.

pulmonary artery anastomosis, this approach still needs to be further developed before being considered for widespread clinical use. First, this approach with the arterial flaps is not feasible for other pulmonary artery anastomoses, such as during pulmonary artery sleeve resections or heart transplantation, due to lack of extra pulmonary artery tissue that can be used to create the flaps. In addition, there would be significant similar difficulty with performing the backwall anastomoses due to lack of space. Second, this approach in lung transplant is only feasible in a specific subset of patients. Any patients with thin, friable, diseased pulmonary arteries would not be good candidates for this approach due to poor tissue quality. Also, many patients have foreshortened hilar vessels, leading to inadequate recipient pulmonary artery length needed to create adequate flaps to perform this technique. Third, with respect to the posterior wall and lung transplant, the authors suggest possibly performing the pulmonary artery anastomosis before the bronchial anastomosis. The potential minimal time saved on the pulmonary artery anastomosis to staple the back wall will be far outweighed by the increased time and difficulty this would cause during the bronchial anastomosis. Thus, overall, while a step in the right direction due to continued innovative thinking, this stapling technique for pulmonary artery anastomosis is not yet ready, nor really feasible, for prime time. Perhaps further development with end-to-end techniques may help solve some of these technical challenges. 


\section{References}

1. Idrees JJ, Yazdchi F, Soltesz EG, Vekstein AM, Rodriguez C, Roselli EE. Outcomes after aortic graft-to-graft anastomosis with an automated circular stapler: a novel approach. J Thorac Cardiovasc Surg. 2016;152:1052-7.
2. Shi J, Liu M, He J, Xu X. A new mechanical method for pulmonary artery anastomosis. J Thorac Cardiovasc Surg Tech. 2021;9:185-7. 